\title{
El Palomar, une communauté de petits producteurs de café a la périphérie du marché mondial
}

Los pequeños caficultores frente a la globalizacion

Small coffee producers and globalization

\section{Kolia Arché}

\section{(2) OpenEdition}

Journals

Édition électronique

URL : http://journals.openedition.org/bifea/6730

DOI : 10.4000/bifea.6730

ISSN : 2076-5827

Éditeur

Institut Français d'Études Andines

Édition imprimée

Date de publication : 1 août 2002

Pagination : 293-322

ISSN : 0303-7495

Référence électronique

Kolia Arché, «El Palomar, une communauté de petits producteurs de café a la périphérie du marché mondial », Bulletin de l'Institut français d'études andines [En ligne], 31 (2) | 2002, mis en ligne le 08 août 2002, consulté le 07 décembre 2020. URL : http://journals.openedition.org/bifea/6730 ; DOI : https:// doi.org/10.4000/bifea.6730

\section{(c)}

Les contenus du Bulletin de l'Institut français d'études andines sont mis à disposition selon les termes de la licence Creative Commons Attribution - Pas d'Utilisation Commerciale - Pas de Modification 4.0 International. 


\title{
EL PALOMAR, UNE COMMUNAUTÉ DE PETITS PRODUCTEURS DE CAFÉ À LA PÉRIPIÉRIE DU MARCHÉ MONDIAL
}

\author{
Kolia ARCHÉ
}

\section{Résumé}

L'importance de la consommation mondiale de café, principalement dans les nations développées, stimule la production dans les pays du sud. Comme matière agricole à grande valeur commerciale, le café rapporte beaucoup de devises aux pays exportateurs.

C'est le cas du Pérou qui écoule $90 \%$ de sa récolte à l'étranger. Cependant, quel est l'avenir des petits caféiculteurs de la province de Chanchamayo, en particulier à Sanchirio El Palomar, qui dépendent des intermédiaires locaux pour vendre leur production ? Élaborant un café de qualité, ils sont pourtant victimes d'un système globalisé qui ne rémunère pas à juste titre les efforts fournis. Le faible prix payé aux petits agriculteurs arrive à peine à couvrir les coûts de production et ne fait qu'accentuer les problèmes de sous-développement.

Ils revient donc à tous les acteurs du café, État, entreprises, associations, mais aussi producteurs, de mettre en place une politique adéquate pour que cette culture, potentiellement rentable, le devienne réellement.

Mots clés : Café, communauté, production, intermédiaire, exportation, marché, politique, Chanchamayo.

\section{LOS PEQUEÑOS CAFICULTORES FRENTE A LA GLOBALIZACIÓN}

\section{Resumen}

La importancia del consumo mundial de café, principalmente en las naciones desarrolladas, estimula la producción en los países del sur. Como materia agrícola de gran valor comercial, el café genera muchas divisas para los países exportadores.

Es el caso del Perú que da salida al $90 \%$ de su cosecha hacia el extranjero. Sin embargo, ¿cúal es el porvenir de los pequeños caficultores de la provincia de Chanchamayo, especialmente para Sanchirio El Palomar, quienes dependen de los intermediarios locales para vender sus productos? Elaborando un café de calidad, sin embargo son víctimas de un sistema globalizado que no recompensa de manera justa sus esfuerzos. El bajo precio pagado a los pequeños agricultores ni siquiera logra cubrir los costos de producción y más bien incrementa los problemas de subdesarrollo.

\footnotetext{
*14 allée du vallon, 26200 - Montélimar. E-mail: archekolia@ hotmail.com
} 
Incumbe así a todos los actores del café, Estado, empresas, asociaciones, pero también productores, de establecer una política adecuada para que este cultivo, potencialmente rentable, lo sea realmente.

Palabras claves: Café, comunidad, producción, intermediarios, exportación, mercado, política, Chanchamayo.

\title{
SMALL COFFEE PRODUCERS AND GLOBALIZATION
}

\begin{abstract}
The importance of coffee's worldwide consumption, mainly in developed countries, stimulates production in the southern countries. As an agricultural product of considerable commercial value, coffee generates a great income for exporting countries.

This is the case of Peru, which exports about $90 \%$ of its production. However, what are the perspectives for small coffee producers from Chanchamayo province, especially the ones from Sanchirio El Palomar, who depend on local traders to sell their products? Producing highquality coffee, they are victims of a globalized system that does not reward their effort fairly. The low price paid to small crop owners is not enough even to cover their production expenses, and it even increases the problems of under-development.

It is up to all the participants in this arena, namely the State, enterprises, associations, and also producers, to establish an adequate policy to regulate this potentially profitable activity and turn it into actually some thing that is profitable.
\end{abstract}

Keywords: Coffee, community, production, traders, exportation, market, policy, Chanchamayo.

\section{INTRODUCTION}

En 1998, des quelques six millions de tonnes de café produites dans le monde, $75 \%$ se sont consommées exclusivement dans les pays importateurs non producteurs que représentent les grandes puissances occidentales. Pour l'année 2000, la production mondiale augmenta à plus de sept millions de tonnes dont $80 \%$ pour l'exportation. En effet, les principaux importateurs de café sont les États-Unis, l'Allemagne, le Japon, la France et l'Italie. À part la Colombie et le Brésil qui consomment 4 kilos de café moulu par an et par habitant (comme aux États-Unis), c'est dans les pays du nord que l'on trouve les plus fortes moyennes : 5,5 kilos en France, 7 kilos en Allemagne et 11,5 kilos pour la Finlande qui détient le record de consommation mondiale par habitant. Au Pérou elle ne dépasse pas 300 grammes.

La forte demande mondiale encourage donc les agriculteurs des pays concernés à produire de grandes quantités. De plus, le café étant beaucoup mieux coté que n'importe qu'elle autre matière première agricole, il semble se poser comme une valeur commerciale sûre permettant l'insertion des caféiculteurs sur le marché international, assurant ainsi l'intégration régionale, mais engendrant aussi une source importante de devises pour les pays. 
Au Pérou, $90 \%$ de la production part pour l'étranger et occupe la troisième place de l'ensemble des exportations. On comprend donc bien les enjeux économiques d'une telle denrée pour les zones agricoles et les populations qui la produisent. Cependant la culture du café n'est pas stimulée par un prix d'achat correct aux petits et moyens producteurs, victimes du monopole des exportateurs et des intermédiaires qui offrent les tarifs les plus faibles, mais aussi à la merci de la fluctuation des prix sur le marché international.

En effet, la plupart des caféiculteurs sont des petits agriculteurs aux ressources limitées, dépendants de facteurs extérieurs qui leurs échappent le plus souvent. Pourtant, élaborer du café dans de bonnes conditions de production et de commercialisation peut constituer une activité suffisamment rémunératrice pour les familles paysannes.

Voyons un exemple avec une communauté de petits producteurs dans la région centrale du Pérou.

\section{LE CAFÉ AU PÉROU}

\section{1. Situation générale nationale}

Parmi les pays producteurs de café le Pérou n'arrive pas en tête de liste, mais au contraire loin derrière les principaux producteurs que sont le Brésil (1,8 millions de tonnes en 1996, 2,3 millions en 1998 et 2,2 millions en 2000), la Colombie (750 000 tonnes en 1996, 760000 en 1998 et 730000 en 2000), et maintenant le Viêt-nam (400 000 tonnes en 1996 et un million en 2000) qui se place au second rang depuis 1999 , reléguant la Colombie au troisième poste. Le café du Pérou participe pour $2 \%$ à la production mondiale (environ 120000 tonnes) et occupe depuis l'année 2000 la $11^{\text {ème }}$ place sur les 50 pays produisant du café (1). Après plusieurs fluctuations, sa production est en constante augmentation depuis le début des années 1990, mais surtout depuis 1994 où la fin de l'époque du terrorisme et la remontée des prix sur la période 1992-1994 ont permis la reprise de cette culture (graphique 1) ; en effet les zones caféières ont été particulièrement touchées par la subversion, notamment la région centrale. En 1990 le pays produisait 80000 tonnes, 105000 tonnes en 1996, 110000 en 1998 et 120000 en 2000. C'est donc une augmentation de $50 \%$ qui stimula l'économie du café entre 1990 et 2000 (2), alors que pendant la période 1996-2000, la production stagna pour la Colombie (3) et n'augmenta que de $18 \%$ au Brésil.

Nous remarquons que généralement les exportations augmentent en fonction de la production, qui sont elles-mêmes stimulées par le cours des tarifs internationaux, à l'exception de ces quatre dernières années où la chute des prix n'a pas influencé la production. Cependant, il est fort probable que la chute continue des prix entraîne la baisse de la production ainsi que celle des exportations. Les bas prix du café ne

(1) Le Pérou occupait le quinzième rang des pays producteurs de café en 1996.

(2) De même pour le Viêt-nam, dont la récolte tripla pratiquement entre 1996 et 2000.

(3) Cependant au Brésil ou en Colombie les quantités produites sont beaucoup plus importantes qu'au Pérou, les variations sont donc moins significatives, quand au contraire l'augmentation est spectaculaire pour le Pérou, compte tenu de sa petite production. 


\section{Graphique 1 : production, exportation et prix moyens du café au Pérou.}

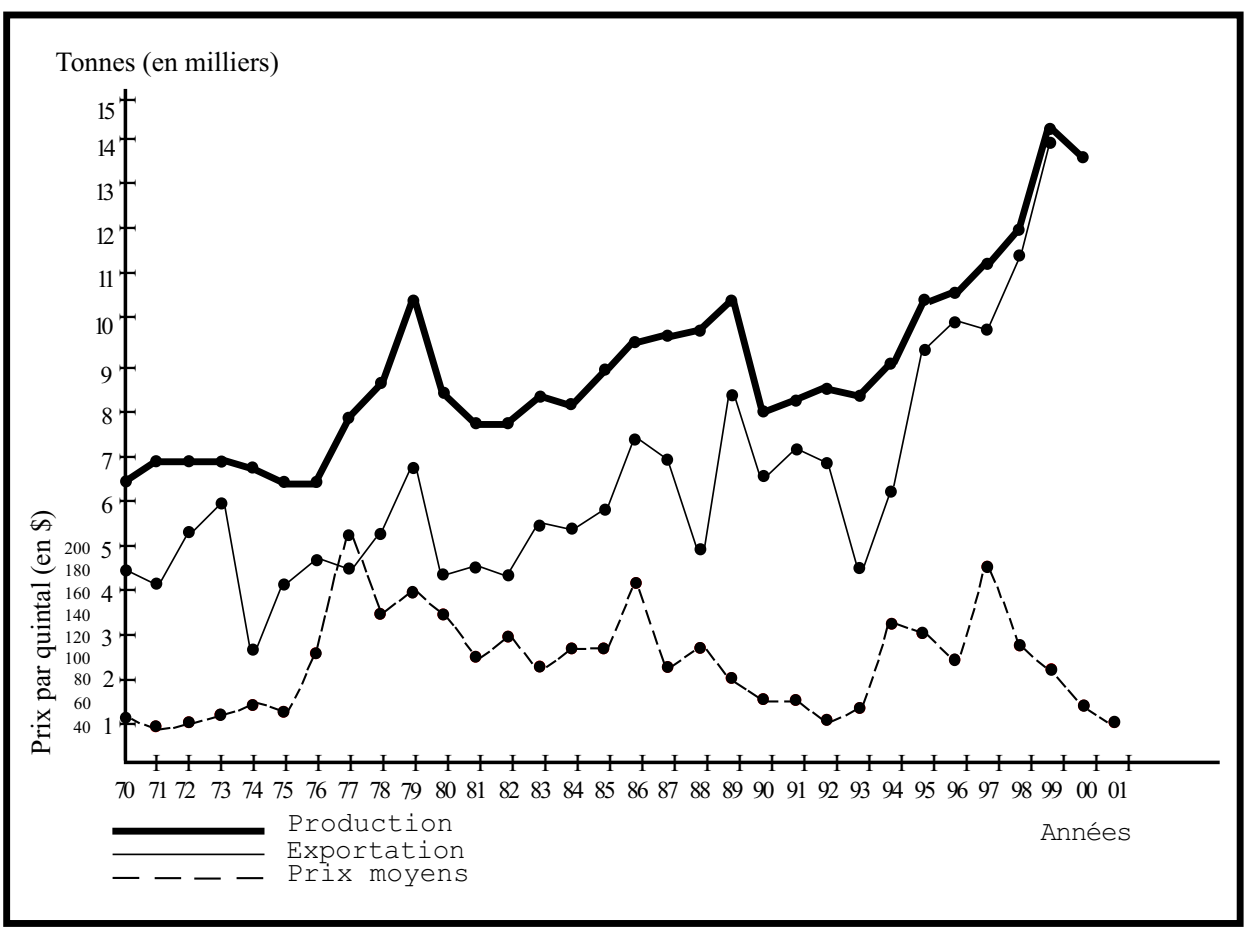

Source : Ministère de l'Agriculture

Slous remarquons que généralement les exportations augmentent en fonction de la production, Ghais qu'elles sont aussi stimulées par le cours des tarifs internationaux. Cependant la chute des Frix peut aussi entraîner l'augmentation des exportations, justement pour tenter de combler le Ganque à gagner, comme nous le notons pour les périodes 1977-1980, 1982-1983, 1988-1989, \$994-1996 et 1997-1998.

C'est depuis 1993 que la production et les exportations connaissent une très forte augmentation.

permettent plus aux producteurs d'utiliser les engrais adéquats pour maintenir un bon rendement des caféières (spécialement vrai chez les petits et moyens caféiculteurs), ce qui risque d'influencer négativement la production.

Le Pérou rentre donc peu à peu en compétition avec les autres pays producteurs, tentant une insertion toujours plus grande sur le marché international. La qualité pur arabica de son café est un des atouts qui pourrait lui faciliter cette intégration mondiale grandissante, sachant qu'à l'heure actuelle c'est l'Allemagne, les États-Unis et le Japon qui sont les principaux consommateurs du café péruvien. 
Le café constitue effectivement le principal produit agricole d'exportation. C'est en moyenne $90 \%$ de la production nationale qui s'oriente vers le marché extérieur, alors qu'en terme de devises, il occupe la première place des exportations agricoles et le troisième rang de l'ensemble des exportations. Le café vendu à l'étranger rapporta presque 400 millions de dollars en 1997 pour l'ensemble de la production nationale, c'est à dire environ la moitié des devises gagnées par la totalité des exportations agricoles. Les expéditions de café sur le marché mondial ont augmenté de façon régulière ces 20 dernières années, passant de 45000 tonnes en 1980 à 115000 tonnes en 1998 et 140000 pour l'année 2000. Exception faite pour les années 1990 à 1993, principalement dû à la chute des cours internationaux de la période 1988-1992 : durant cette phase, le prix du quintal de café vert tomba à 60 dollars en moyenne, alors qu'en général il oscille autours de 120 dollars (un quintal de café vert équivaut à $46 \mathrm{~kg}$ ) (se référer au graphique 1). Au début de l'année 2001, le prix du quintal était de nouveau inférieur à 60 dollars, alors qu'il ne vaut plus que 46 dollars en ce début d'année 2002.

À l'échelle nationale il existe 213000 hectares de plantations de café en production, qui sont la propriété de 110000 agriculteurs. Cela fait une moyenne d'environ 2 hectares par agriculteur, qui masque cependant une très grande disparité dans les unités de production, entre les micro producteurs qui possèdent à peine un demihectare et les très gros agriculteurs dont certains disposent de plusieurs centaines d'hectares.

Bien que le rendement à l'hectare se soit élevé en moyenne de 500 kilos en 1990 à 600 kilos en 1998, c'est à dire environ 12 quintaux de café, de fortes différences persistent entre les gros producteurs utilisant des techniques modernes (jusqu'à 70 quintaux par hectare) et les petits paysans dont le rendement par hectare des cultures traditionnelles en zones isolées est parfois inférieur à 5 quintaux, voire moins de un quintal pour les communautés natives qui n'ont aucun moyen.

Il est intéressant de noter que la surface cultivée en café a été multipliée par 30 au cours des 45 dernières années, ce qui montre l'importance économique d'une telle culture, encourageant l'extension ou la création de nouveaux domaines. Les cultures caféières se caractérisent en effet par un fort potentiel économique si nous considérons la haute valeur commerciale du café. Comparant son prix de vente par rapport au reste des denrées agricoles du Pérou, le café obtient de loin les tarifs les plus élevés. À la fin de la récolte de l'année 2000 le kilo de café sec s'est vendu sur le marché national environ 3,50 soles au prix de gros. À la même période la plupart des autres matières premières agricoles arrivaient à peine à un demi-sol par kilo (pomme de terre : $0,45 \mathrm{~s} /$. ; ananas : $0,60 \mathrm{~s} /$. ; maïs : 0,40 s/. ; avocat : 0,45 s/. ; banane : 0,20 s/. ; manioc : 0,40 s/.).

\section{2. Les principales régions productrices}

\section{2. 1. Six grandes régions}

La production de café au Pérou se répartit en 6 grands secteurs appartenant tous au piémont oriental de la chaîne andine (Tableau 1 ; Fig. 1). Cependant les technologies de productivité ne sont pas des plus performantes (en comparaison du Costa Rica ou du Brésil) et d'autres facteurs externes viennent perturber le bon déroulement de cette activité. 
Tableau 1 - Principales régions productrices de café (1998).

\begin{tabular}{|c|c|c|c|}
\hline $\begin{array}{c}\text { Régions } \\
\text { productrices }\end{array}$ & $\begin{array}{c}\text { Nombre } \\
\text { d'exploitants }\end{array}$ & $\begin{array}{c}\text { Nombre } \\
\text { d'hectares }\end{array}$ & $\begin{array}{l}\text { Production } \\
\text { (en tonnes) }\end{array}$ \\
\hline $\begin{array}{c}\text { région } 1 \text { : Junín } \\
\text { et Pasco }\end{array}$ & 19210 & 64490 & 33500 \\
\hline Junín & 17000 & 57770 & 28600 \\
\hline Pasco & 2210 & 6720 & 4900 \\
\hline $\begin{array}{c}\text { région } 2 \text { : } \\
\text { Cajamarca } \\
\text { et Amazonas }\end{array}$ & 38400 & 65230 & 39000 \\
\hline Cajamarca & 26170 & 45430 & 35000 \\
\hline Amazonas & 12230 & 19800 & 4000 \\
\hline $\begin{array}{c}\text { région } 3 \text { : } \\
\text { Cusco et Puno }\end{array}$ & 20860 & 39495 & 22500 \\
\hline Cusco & 17560 & 34695 & 18000 \\
\hline Puno & 3300 & 4800 & 4500 \\
\hline $\begin{array}{c}\text { région } 4 \text { : } \\
\text { San Martín } \\
\text { et Huánuco }\end{array}$ & 15750 & 22970 & 12900 \\
\hline $\begin{array}{l}\text { San Martín } \\
\text { Huánuco }\end{array}$ & $\begin{array}{r}11770 \\
3980 \\
\end{array}$ & $\begin{array}{r}17380 \\
5590 \\
\end{array}$ & $\begin{array}{r}11000 \\
1900 \\
\end{array}$ \\
\hline région 5 : Piura & 5760 & 6700 & 3200 \\
\hline $\begin{array}{l}\text { région 6: } \\
\text { Ayacucho }\end{array}$ & 3540 & 4990 & 5500 \\
\hline
\end{tabular}

Source : Ministère de l'Agriculture.

Le premier secteur est la région centrale qui regroupe les départements de Junín et de Pasco qui, comme nous l'avons dit antérieurement, a beaucoup souffert des problèmes liés au terrorisme. Entre 1987 et 1995 la majorité des agriculteurs a dû abandonner leur plantation, sous la pression constante des différents groupes subversifs et de la confusion de l'armée. La destruction de cultures, de machines nécessaires à la transformation du café et l'abandon des parcelles par leur propriétaire, occasionna la régression de la production. Aujourd'hui il existe toujours de nombreux hectares en friche, notamment chez les petits producteurs qui manquent de ressources financières pour réhabiliter les plantations. Néanmoins il s'agit d'une des principales zones de production, nous revenons ensuite plus en détail sur cette région. 


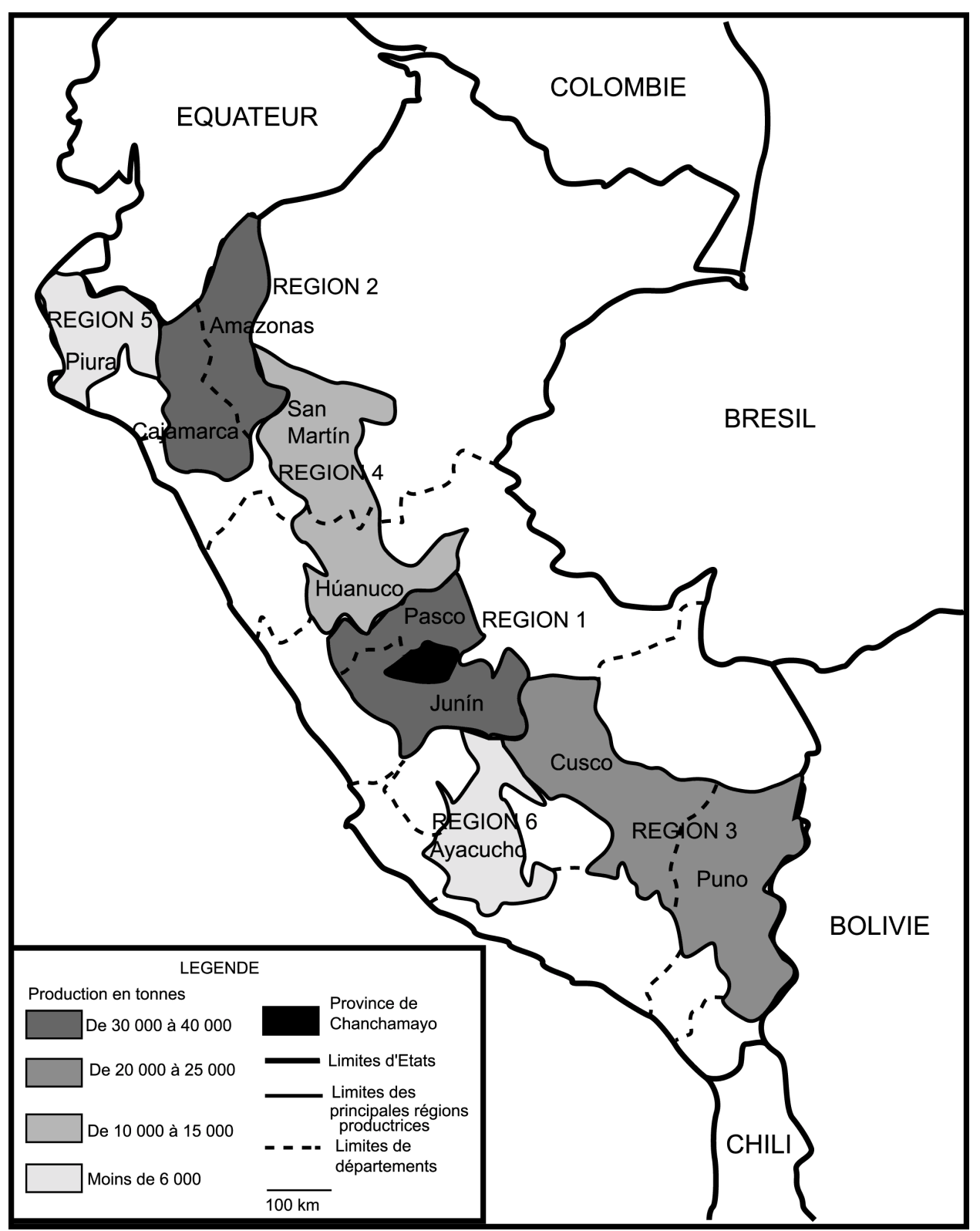

Fig. 1 - Pérou, les principales régions productrices de café. 
Le second secteur est constitué par les départements de Cajamarca et Amazonas. C'est, avec la région centrale, la zone de production la plus importante du pays. Elle détient $33 \%$ des caféières du Pérou. Depuis la dernière décennie, sa superficie cultivée en café a énormément augmenté. Elle a triplé rien que pour la province de Nuevo Cajamarca qui produit à elle seule environ 7000 tonnes par an. Il semble que ce soit une région d'avenir pour le café péruvien compte tenu des excellentes conditions climatiques et de l'accès direct au port de Chiclayo.

Les départements de Cusco et Puno forment le troisième secteur. Bien que possédant $20 \%$ de la superficie totale nationale, pendant longtemps le faible niveau technologique de la post récolte entraîna la production d'un café de mauvaise qualité. La province de Quillabamba, responsable de plus de $90 \%$ des récoltes, se détache progressivement du lot, produisant depuis peu un café de grande qualité, directement exportable sur le marché des cafés spéciaux des États-Unis.

Le quatrième secteur concerne celui des départements de San Martín et Huánuco, où depuis une vingtaine d'années une partie de leur surface cultivée a disparu au bénéfice de la culture de la coca, dont la transformation en pâte basique de cocaïne assure une plus-value énorme sur les marchés internationaux et des meilleurs revenus aux agriculteurs. C'est une conséquence de l'instabilité du prix du café.

Dans la zone du département de Piura, qui ne représente pourtant que $3 \%$ de la superficie caféière du pays, les techniques productives se sont largement améliorées, bien que la production ne soit pas encore significative dans l'ensemble.

Le dernier secteur est celui d'Ayacucho qui a connu lui aussi les graves problèmes de subversion, responsables de l'abandon des cultures. En grande partie toujours en friche, ce département ne produit plus que 3500 tonnes par an.

\section{2. 2. La région centrale}

$32 \%$ de la surface cultivée en café est localisée dans la région centrale formée par les départements de Junín et Pasco, dont 90 \% pour le seul département de Junín (les régions en tant qu'entité administrative regroupant plusieurs départements n'existent plus depuis juillet 1998, chaque département se caractérise maintenant comme une région). Cette zone possède 65000 hectares pour un total de 19000 agriculteurs. Une moyenne de trois hectares par producteur (un peu plus que la moyenne nationale), qui ne change rien aux disparités parcellaires entre agriculteurs. La plupart des caféiculteurs sont considérés comme petits (de 0 à 5 hectares) ou moyens producteurs (de 5 à 20 hectares). Sa production atteint environ 35000 tonnes à l'année pour un rendement d'environ 12 quintaux à l'hectare.

Au total, principalement trois provinces sont concernées par la culture du café dans la partie du piémont amazonien dont le climat tropical convient très bien à ce type d'agriculture ( $C f$. tableau 2) : Oxapampa pour Pasco, Chanchamayo et Satipo pour Junín. 
Tableau 2 - Production de café dans la région centrale (1998).

\begin{tabular}{|c|c|c|c|}
\hline Province & $\begin{array}{c}\text { Nombre } \\
\text { d'exploitants }\end{array}$ & Nombre d'has & Production (tonnes) \\
\hline Chanchamayo & 9273 & 36330 & 20700 \\
Satipo & 7228 & 19860 & 11500 \\
Oxapampa & 2178 & 6700 & 4900 \\
\hline
\end{tabular}

Source : Ministère de l'Agriculture.

Bien que le département de Pasco ne représente que $10 \%$ des plantations de la région, il regroupe les agriculteurs les mieux intégrés au marché mondial. Une grande partie de la production d'Oxapampa est exportée directement vers les États-Unis et l'Allemagne.

C'est cependant le district de Villa Rica qui produit l'essentiel du café de la province (plus de $95 \%$ ). On y rencontre effectivement de très gros producteurs qui sont généralement les descendants de familles d'immigrés allemands et italiens, qui ont quitté leurs terres natales il y a un peu plus d'un siècle pour venir s'installer dans cette région au climat tempéré et se dédier a la caféiculture et à l'élevage. Les techniques de production employées sont les plus développées de tout le pays (le district de Villa Rica produit 100000 quintaux par an, soit 4600 tonnes), les rendements sont les plus élevés (environ 15 quintaux par hectare en moyenne) et la caféiculture très moderne peut se comparer à celle du Costa Rica.

Nous pouvons prendre quelques exemples en guise d'illustration. Les frères Ingo et Diter Noche disposant de 270 hectares produisent 5000 quintaux à l'année. Les frères Juan et Klemens Brack récoltent 3000 quintaux par an de leurs 170 hectares. Cela représente une moyenne de plus ou moins 20 quintaux par hectare qui indique l'application d'une technologie agricole avancée, rendue néanmoins possible par un investissement de départ adéquat et conséquent (4).

L'intégralité de la production de ces agriculteurs s'exporte vers les États-Unis ou l'Europe. Un investissement, un processus et une structure qui n'est pas possible pour un petit producteur isolé, qui implique aussi une organisation particulière des cultures dans l'espace, avec un aménagement adéquat du territoire (chemin d'accès aux plantations, zone de transformation et de stockage du café) et la mise en place de filières d'exportation.

Pour Junín, c'est la province de Chanchamayo qui concentre $60 \%$ de la surface cultivée en café et qui fournit plus de $70 \%$ de la production du département. Pratiquement $70 \%$ des terres agricoles de la province sont consacrées à la culture du café. Cette zone de réputation mondiale pour la qualité de son café détient aussi le titre de capitale caféière du pays, par la position de La Merced, chef lieu provincial. Un des

(4) Nous pourrions aussi citer le cas de Javier Schuler, dont une partie de ses 60 hectares produisent entre 50 et 70 quintaux par an et par hectare 
avantages de Chanchamayo est la proximité du port du Callao où la production est acheminée pour l'exportation. Le gros problème réside cependant dans l'accaparement de presque l'intégralité de la production par les intermédiaires locaux qui payent à un très bas prix le café aux agriculteurs et qui se chargent de l'exportation, réalisant ainsi des bénéfices importants. Dans la province on rencontre essentiellement des petits et moyens caféiculteurs dont le manque d'organisation les rend victimes des dures conditions du marché et de la loi des intermédiaires.

Face à de telles contraintes, la solution consiste alors à s'associer en coopérative. Permettant le regroupement de plusieurs petits et moyens producteurs organisés au sein de la même entité, l'accès au crédit public est ainsi facilité et chaque producteur peut alors valoriser sa plantation. L'organisation des paysans est effectivement une des conditions pour recevoir crédits et assistance technique de la part du gouvernement. L'ouverture vers le marché international est favorisée par l'association des agriculteurs pour lutter contre le monopole des intermédiaires et disposer de machines nécessaires à la transformation du café, pour s'assurer une autogestion et ouvrir des filières d'exportations. Profitant de ces avantages la coopérative peut se créer un capital, dont une partie est réinvestie dans des actions de développement pour le bénéfice des communautés des associés. Ce schéma devient réalité pour ce qui est des grandes coopératives regroupant un nombre important d'agriculteurs et comptant ainsi sur une structure productive, administrative et commerciale adéquate.

Dans la province de Chanchamayo sont aussi localisées les plus grandes coopératives de toute la région centrale. La Florida, basée à La Merced et créée en 1966, regroupe 1800 petits agriculteurs provenant de 36 communautés rurales de la même zone, produit environ 57000 quintaux par an directement pour l'exportation, réinvestit une partie des bénéfices dans des programmes de développement pour les villages de ses membres (construction de route, d'écoles, endiguements des rivières, mise en place de services médicaux, électrification) et promeut le crédit, l'assistance technique et la diversification des cultures. Échappant aux intermédiaires locaux, elle achète le café à ses associés à un prix plus valorisant.

La coopérative Chanchamayo, créée en 1996, possède plus ou moins les mêmes caractéristiques que sa consoeur, et leurs objectifs communs visent à revaloriser une zone qui a souffert des effets néfastes du terrorisme.

Nous voyons dans la seconde partie le cas précis d'une communauté de petits et moyens producteurs organisés en une entreprise communale, conjointement à ses problèmes d'intégration sur le marché et d'accès à un niveau de développement respectable (5).

(5) Face aux contraintes et exigences des marchés extérieurs, même les gros producteurs s'associent parfois entre eux pour engendrer une force d'action plus efficace, comme dans le cas de la coopérative Villa Rica Highland, regroupant les familles Brack, Noche et Marin. Localisée dans la province de Chanchamayo, ses associés cultivent dans le département de Pasco (district de Villa Rica) une surface d'environ 520 hectares, exportant la majorité de la production. 


\section{3. Le café comme espace pionnier}

Les cultures de café se caractérisent par des surfaces gagnées sur la forêt. Ce sont les populations de la côte et de la sierra qui ont colonisé tardivement la zone du piémont amazonien, pour exploiter les terres fertiles, en organisant ainsi un espace pionnier, modifiant les anciennes structures traditionnelles locales (Girot, 1984). En effet, la découverte de la région de Chanchamayo se doit au missionnaire franciscain Fray Gerónimo Jiménez en 1635, c'est à dire un siècle après la colonisation du Pérou. Ce n'est qu'à partir de 1650 que les premières missions réussirent à s'établir dans la région. Cependant, compte tenu des grandes résistances des populations indigènes (Asháninca et Campa) la colonisation fut rendue difficile (Barclay \& Santos Granero, 1995).

Malgré la proximité de la capitale, l'implantation des populations immigrées se fera à un rythme relativement lent en comparaison des zones minières de la sierra, car dépourvue de métaux précieux, ce secteur tropical ne représentait pas d'intérêt particulier pour la Vice-royauté. Néanmoins, avec les quelques missions en place et avec l'essor des centres miniers des hauts plateaux voisins, une économie d'hacienda (coca et canne à sucre) se développa progressivement, surtout depuis la fin du $17^{\mathrm{ème}}$ siècle, grâce à la main-d'oeuvre indigène asservie. Il s'agissait de fournir de la coca, de l'eau de vie et du sucre aux travailleurs des mines de Cerro de Pasco. La culture du café était alors à son stade expérimental.

Cette articulation économique entre la forêt tropicale et la sierra fut brutalement interrompue par le soulèvement indien de 1742. La destruction des haciendas et la chasse des colons permit la récupération des territoires autochtones et la constitution d'une zone autonome qui restera en vigueur pendant près d'un siècle.

Ce n'est qu'avec la stabilisation politique qui marque la fin des luttes pour l'indépendance et l'augmentation de la production minière, que la colonisation de la selva (6) centrale reprendra son cours. Une forte demande en eau de vie provoqua l'insistance de l'oligarchie tarménienne à ce que le pouvoir central permette le retour à cette zone fertile. C'est finalement en 1847 que s'ouvre l'axe Tarma-Chanchamayo, entraînant l'émigration massive dans cette zone, rendue d'autant plus facile par l'adjudication de terres aux nouveaux colons. C'est ainsi que fut fondée en 1869 la colonie de La Merced, capitale actuelle de la province de Chanchamayo. De grands domaines s'établirent, ou se renforcèrent, comme celui de la Colonie Perené qui appartenait à la Peruvian Corporation, puissante entreprise anglaise.

En raison de la guerre avec le Chili, la production minière déclina et le marché de l'eau de vie se réduisit considérablement. À la fin du $19^{\text {ème }}$ siècle les cours mondiaux du café subirent une hausse importante, conséquence des fortes gelées de 1870 au Brésil, entraînant la chute de la production nationale. L'Amérique latine et les Caraïbes (Surinam, Brésil, Jamaïque, Haïti, Antilles, Cuba...) produisaient déjà du café depuis presque un siècle, date de l' augmentation de la consommation dans les pays colonisateurs, qui avaient découvert cette boisson parfumée dans les contrées orientales.

(6) Forêt tropicale. 
Une nouvelle phase de migrations s'impulsa alors en direction de Chanchamayo, à laquelle participèrent de nombreux colons européens (Allemands et Italiens). La canne à sucre céda la place aux cultures de café et l'articulation économique entre la sierra et la selva prit fin au profit d'une nouvelle orientation de la production locale en direction de Lima à des fins d'exportation. Les réseaux commerciaux et des transports se modifièrent alors pendant que s'installèrent, dans les principales villes, les places financières créditrices des nouveaux planteurs caféiers (maisons commerciales et banques). On assistait donc à une nouvelle organisation du territoire et à la mise en place d'une forte identité fondée sur le café, qui confère aujourd'hui à La Merced le titre de " capitale caféière " du pays. Chanchamayo s'articulait alors directement avec Lima pour s'insérer dans la sphère du monde extérieur.

Un ample processus de colonisation dont la mise en place de cultures nouvelles se traduit par une avancée sur les contrées encore vierges de la forêt tropicale d'altitude. Les déboisements à outrance au détriment de l'écosystème, marquent alors la forte anthropisation de l'espace, qui s'aménage en une série de villes principales (La Merced, San Ramón) reliées en réseaux à leurs centres secondaires et aux zones rurales cultivées, dont elles dépendent largement. La selva centrale se convertit en l'un des fronts pionniers les plus important du pays, entraînant le recul toujours plus loin des populations indigènes. La vague des déboisements engendra aussi de conséquences négatives sur l'environnement, créant des phénomènes d'érosion démesurés.

Malgré les fluctuations du prix du café, avec cependant des périodes de hausses représentatives, Chanchamayo continuait d' attirer les populations, principalement de la sierra, à un rythme soutenu jusque dans les années 1960, où s'enregistrent d'ailleurs les meilleurs tarifs. La croissance démographique sera très forte avec des taux annuels de plus de $5 \%$ entre les années 1960 et 1980 . Le café représente toujours la culture dominante de la province.

La disparité dans la taille des propriétés caféières morcelait l'espace entre haciendas et petites plantations, ce que viendra tenter de corriger la réforme agraire du général Velasco en 1969. Une partie seulement des grands domaines furent démantelés et les terres passaient sous juridiction des communautés voisines. La Peruvian Corporation qui possédaient de grandes extensions dans la province de Chanchamayo, vit son territoire amputé et divisé entre différentes communautés du secteur (Barclay, 1989). La Peruvian Corporation représentait jadis l'entreprise monopolisatrice par excellence, puisqu'elle avait eu, jusqu'à la politique de nationalisation du Général Velasco, le contrôle du chemin de fer par lequel transitaient les minéraux des hauts plateaux à la côte. D' abord aux mains du capital anglais et ensuite américain, elle gérait une grande partie de l'articulation économique entre les Andes et la côte, avec son aire d'influence sur la selva.

\section{EL PALOMAR, UNE COMMUNAUTÉ DE PETITS PRODUCTEURS}

L'exemple précis d'une communauté nous permet de mieux comprendre les problèmes d'intégration des petits producteurs de café dans une économie mondialisée. $90 \%$ du café péruvien étant exporté, les agriculteurs se trouvent bien dans une situation de dépendance totale du marché international qui fixe les règles du jeu et détermine les conditions du développement local. 
Le cas de la zone de El Palomar est tout à fait représentatif d'une communauté de petits et moyens caféiculteurs qui, après avoir souffert de la subversion et abandonné leur culture, est aujourd' hui en plein processus de restructuration et de réhabilitation des plantations pour tenter une nouvelle forme d'intégration sur le marché mondial, par la spécialisation de la production et de son réseau de vente, pour échapper ainsi aux intermédiaires locaux.

\section{1. El Palomar, zone caféière}

La zone de El Palomar s'étend sur environ 12000 hectares dont la majeure partie est constituée de forêt tropicale peu exploitée, où existent encore de grands espaces vierges (Fig. 2). Accrochée sur le versant est de la cordillère des Andes dans la province de Chanchamayo, elle se divise en plusieurs petits villages dont l'altitude varie de 1300 $\mathrm{m}$ à $1750 \mathrm{~m}$.

La colonisation du secteur de El Palomar est très récente. Bénéficiant de terrains que la Peruvian Corporation avait vendu à l'État, en 1923 un groupe d'une dizaine de colons provenant des Andes centrales commence à occuper les terres. En 1926 le

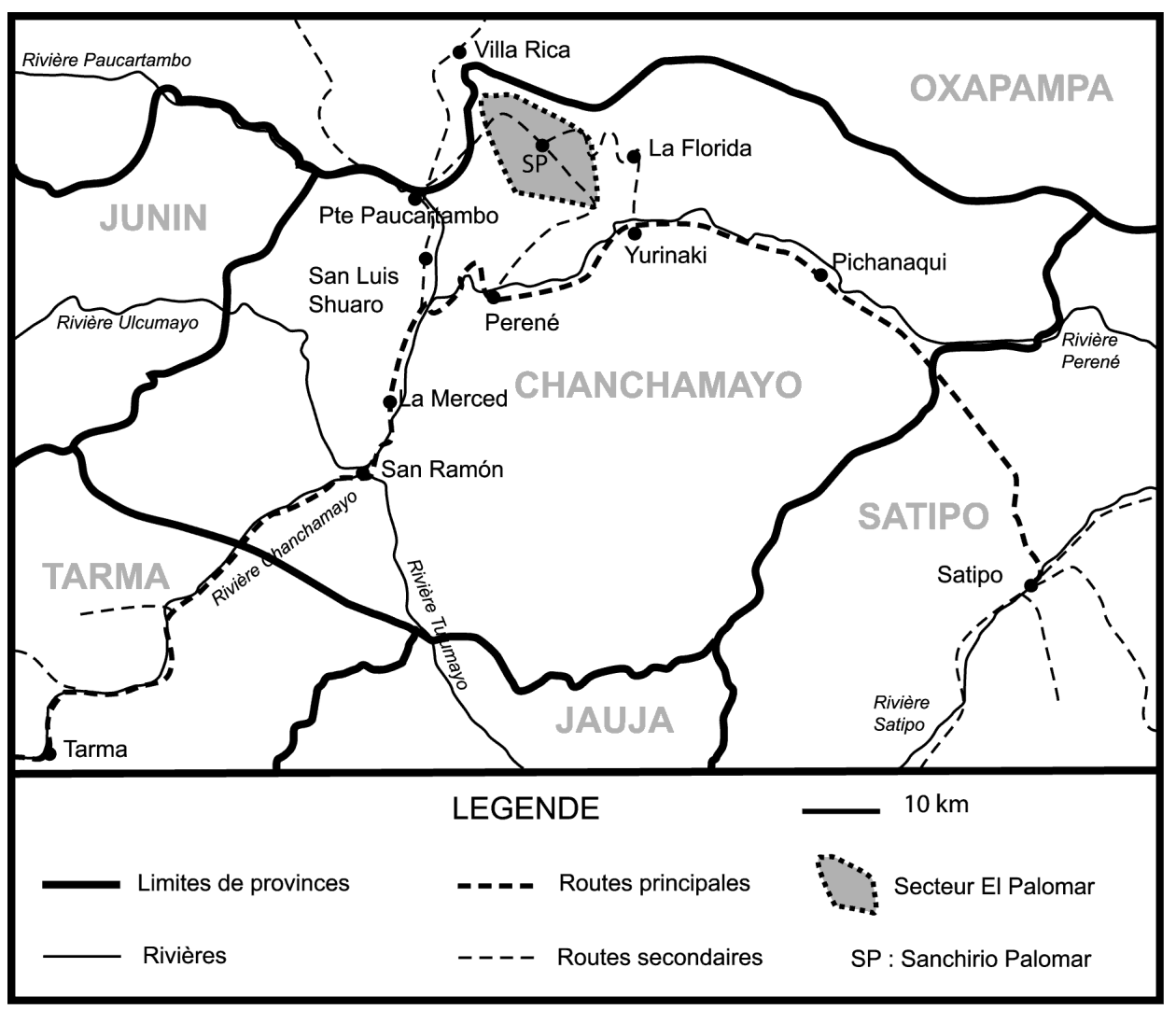

Fig. 2 - Région de El Palomar. 
gouvernement décrète une Résolution Suprême qui octroie à chacun d'eux 50 hectares pour la modique somme de $1 \mathrm{sol}$ par hectare. En 1946 la population avait atteint un total de 118 colons, puis le 6 août 1954 est fondé officiellement le village de Sanchirio comprenant déjà cinq annexes.

Au début des années 1960 environ 300 familles peuplaient déjà la zone. L'attrait de nouvelles terres à mettre en valeur engendrait de constantes migrations principalement depuis les Andes centrales, mais aussi depuis la côte. Aujourd'hui Sanchirio Palomar, le chef-lieu, abrite la majorité de la population. 200 familles y vivent, alors que le reste, environ 600 familles, se répartit entre les 12 annexes qui comprennent de 30 à 80 foyers selon l'importance. La communauté tire son nom de la langue indigène Asháninca, dans laquelle Sanchirio signifie " eau froide".

Le territoire s'organise en un habitat concentré dans le village principal et dans les hameaux, autours desquels se trouvent les parcelles de cultures vivrières, quand il

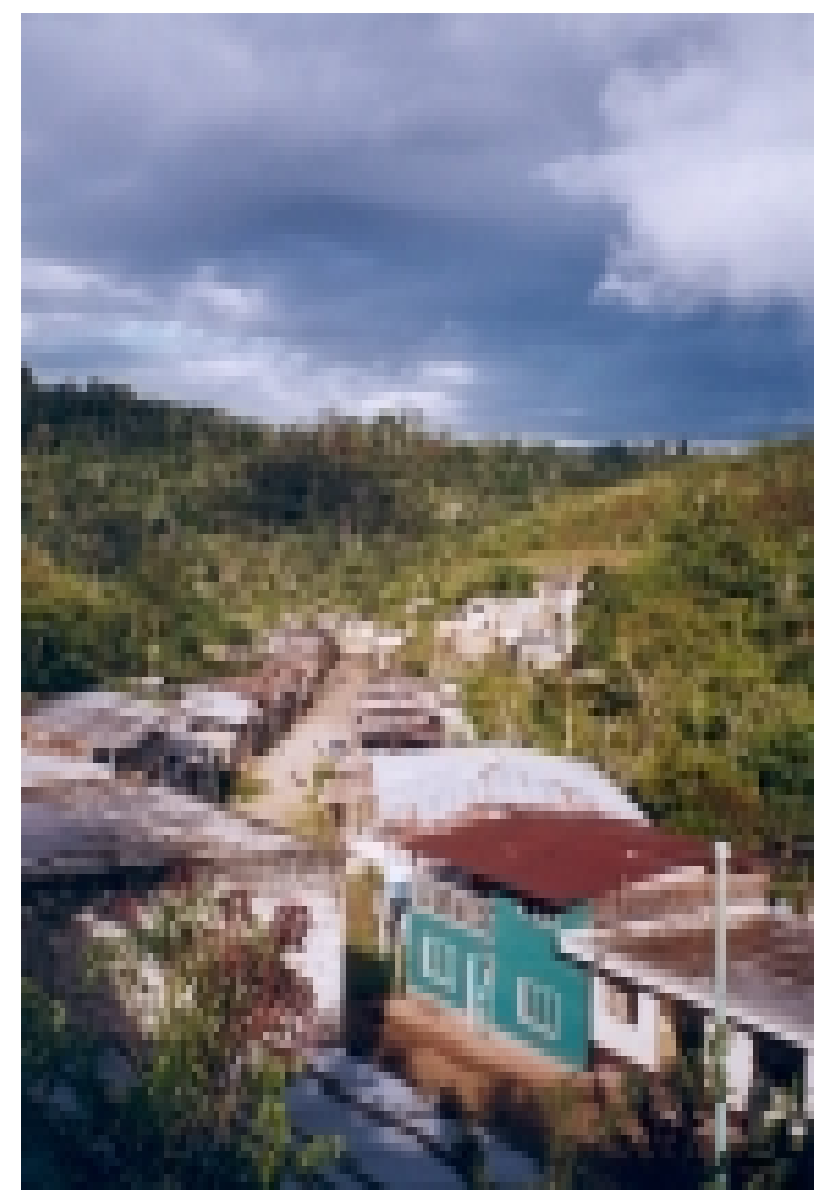

Fig. 3 - Rue principale du village de Sanchirio. 
y en a. Les plantations de café sont habituellement plus éloignées des zones peuplées, en altitude.

Chaque annexe est reliée au chef-lieu, par un chemin carrossable pour les plus importantes, mais plus souvent par un sentier muletier. Sanchirio, au coeur du territoire communal, confère au réseau routier une forme étoilée, connectant le centre à sa périphérie. Les relations entre Sanchirio et ses hameaux, sont quotidiennes, les gens de l'extérieur venant au centre de la communauté pour disposer des services existants : collège, poste de santé, épiceries, bus. Les agriculteurs se déplacent aussi tous les jours de leur village jusqu'aux cultures.

À El Palomar, tous les habitants sont des agriculteurs et $98 \%$ des revenus provient de la vente du café. Chaque famille possède en moyenne trois hectares de plantations de café, qu'elle combine en général avec une ou plusieurs parcelles de cultures vivrières. Les champs sont à flanc de montagne, sur des pentes souvent très prononcées, ce qui rend difficile les conditions de travail. Les chemins d'accès aux caféiers sont parfois très abrupts, compliquant les déplacements, notamment quand il faut transporter la récolte au lieu de traitement, dans les annexes ou à Sanchirio. Un petit nombre de familles est aussi propriétaire d'une parcelle ou deux de produits agricoles réservés à la vente, en complément des revenus du café (banane, avocat, ananas ou piment).

Dans la zone de El Palomar, toutes les conditions sont réunies pour produire un café d'excellente qualité. C'est tout d'abord l'altitude qui confère aux grains une saveur particulièrement agréable. Les variétés d'arabica utilisées, comme la Typica, le Bourbon ou le Caturra, renferment de très bonnes caractéristiques aromatiques et, en plus, elles sont résistantes aux maladies.

Les plantations grandissent à l'ombre de grands arbres, le Pacay (7)évitant ainsi la brûlure des rayons du soleil pendant la floraison des caféiers. Une trop forte exposition solaire occasionne fréquemment la chute des fleurs, empêchant donc la formation des fruits, conséquence dramatique pour l'agriculteur qui perd une grande partie de sa récolte. Il faut donc réussir à aménager une ombre adéquate, sans trop d'obscurité car le fruit a aussi besoin de soleil et de chaleur pour arriver à maturité.

La présence d'arbres est aussi une forme de culture écologique qui préserve l'écosystème. Les racines favorisent la conservation du sol, empêchant l'érosion, et la partie aérienne assure l'habitat des espèces animales (singes, oiseaux), respectant ainsi l'environnement. La chute des feuilles fournit de la matière organique aux caféiers, en produisant une épaisse couche d'humus, indispensable pour la croissance des plantes, évitant des dépenses supplémentaires en engrais pour les paysans dont les ressources sont limitées. Une ombre bien contrôlée garantit aussi une faible présence de maladie, réduisant les coûts en fongicides et insecticides éventuels. Trop d'ombre entraîne effectivement un fort degré d'humidité, source de moisissures et de maladies.

Au mois d'avril commence la récolte qui s'achèvera vers la fin août. Toute la famille y prend part. Il s'agit d'une récolte sélective où on cueille seulement les grains bien mûrs, appelés café cerise pour sa couleur et sa taille. Ce procédé est fastidieux car il faut effectuer plusieurs passages dans chaque parcelle. Ceux qui possèdent une surface

(7) Connu aussi sous le nom de Inga. 
plus grande embauchent parfois des ouvriers saisonniers venus de la sierra ou des familles voisines.

Les grains sont déposés dans des paniers en osier, et descendus le jour même sur les lieux de traitement (planta de beneficio). Il faut d'abord enlever la première écorce rouge (pulpe du café) avec une machine spéciale. La décomposition de cette pulpe servira plus tard de matière organique utile aux plantes. Le café subit alors une courte fermentation dans des bassins en ciment, il est ensuite lavé avec de l'eau bien propre pour en retirer une couche collante, le mucilage. Les grains sont alors prêts pour être séchés au soleil sur des grandes dalles en béton.

Toutes ces techniques de cultures traditionnelles et économiques sont adaptées aux possibilités financières des agriculteurs de El Palomar qui utilisent quelques engrais naturels peu coûteux comme le guano marin, de poules ou de mouton et la roche phosphorique, mais surtout la matière organique de la pulpe en décomposition fournie gratuitement par la nature.

Le café sec est ensuite transporté à La Merced pour y être vendu. Les acheteurs se chargent de la dernière étape avant l'exportation, qui consiste à enlever la seconde écorce du café sec pour obtenir le grain vert.

Les conditions climatiques et la fertilité des sols sont donc favorables à la culture du café. Contrairement à la zone andine d'altitude, la clémence des températures et l'abondance des pluies permettent aussi une plus grande diversité des cultures, assurant en partie l'autosubsistance alimentaire. Manioc, maïs, banane, papaye, avocat et ananas poussent facilement sans la crainte de gelées ou de sécheresses éventuelles.

\section{2. Isolement et pauvreté}

Bien qu'il semble que El Palomar bénéficie de certains avantages, les contraintes du milieu n'en restent pas moins importantes. En plein piémont andin, le relief escarpé du secteur ne facilite pas les déplacements, si bien que les quelques chemins carrossables à l'intérieur de la zone de El Palomar sont totalement impraticables pendant la saisons des pluies. C'est alors hommes, mules et chevaux qui se chargent du transport des marchandises et de la production entre les différents hameaux et Sanchirio. Les fortes pentes et les accidents de terrains rendent aussi les conditions de travail agricole difficiles et pénibles.

De plus, en plein coeur de la forêt tropicale d'altitude, la communauté rurale de El Palomar est isolée du reste du pays. C'est le village de Sanchirio, à 1500 m, qui est le mieux relié à la ville la plus proche, La Merced, capitale de la province, à 2 heures de voiture par un chemin de terre, elle-même à 8 heures de bus de Lima. Très peu des autres annexes sont connectées au réseau routier, ce qui les éloigne de 4 heures de marche du chef-lieu pour les plus reculées et augmente les coûts de transport des marchandises.

Les nombreux glissements de terrains sur la route allant à La Merced rendent difficile la connexion de la zone avec l'extérieur durant la saison des pluies. Pour rejoindre La Merced il faut alors entreprendre une descente de 3 heures à pied jusqu'au premier point où passe un service de minibus, en provenance de Oxapampa (département 
voisin de Pasco), dans la vallée de Paucartambo. Jonction nécessaire aussi en saison sèche en raison du peu de véhicules assurant la liaison entre La Merced et Sanchirio (8).

L'isolement de la zone détermine aussi les conditions de son développement. Seul le chef-lieu profite depuis trois ans d'un réseau hydroélectrique privé, mais restreint, qui fournit l'électricité au village pendant 3 ou 4 heures à la tombée de la nuit. C'est en fait un des agriculteurs qui a installé un générateur fonctionnant avec le courant de la rivière et qui vend l'énergie au reste des habitants, car le village n' est bien sûr pas relié au réseau national. Il n'y a pas non plus de téléphone, pas même un poste communautaire. L'eau est le seul service qui està peu près bien réparti, dans lechef-lieu et deux des hameaux principaux, mais personne ne dispose d'un quelconque système d'égout.

Quelques épiceries regroupées principalement à Sanchirio, approvisionnent les habitants en produits de base. L'inexistence d'un marché hebdomadaire réduit considérablement l'ampleur des mouvements commerciaux à l'intérieur de la communauté et confirme une économie restreinte. Les habitants doivent alors se rendre à La Merced pour acheter vêtements, outils et autres articles indispensables, mais aussi pour recourir aux services nécessaires comme les banques, les hôpitaux, l'administration publique ou les institutions privées de financement, établissant ainsi des relations particulières entre la communauté et la ville.

Chaque annexe possède une école, mais il y a un seul collège pour l'ensemble de la zone, dans le village de Sanchirio, ce qui rend problématique l'assistance régulière des élèves venant des hameaux reculés. Le manque de professeurs ainsi que leur peu de qualification conduisent à un enseignement de mauvaise qualité. De plus, en raison de l'isolement de la communauté et des problèmes de communication, l'absence de ces derniers est relativement fréquente. Le niveau de l'éducation n'est donc pas bon, ce qui laisse très peu d'opportunité aux jeunes qui voudraient tenter leur chance dans les universités du pays, pour envisager un autre avenir que celui de petits paysans soumis aux dures lois du marché international. Seulement 1,5\% des jeunes font des études universitaires à Tarma, Huancayo ou Lima.

En ce qui concerne le secteur santé, la situation est elle aussi critique. Il ne reste qu'un poste de santé, à Sanchirio, très mal équipé, avec un personnel plus que réduit, puisque 6 personnes dont un unique médecin doivent s'occuper de la santé des 800 familles, tâche impossible. Le manque de budget en provenance du pouvoir central ainsi que les détournements de fonds de la part de la capitale du district, San Luis de Shuaro, ont obligé la fermeture des deux infirmeries annexes qui permettaient avant une meilleure distribution de l'assistance médicale. Seuls fonctionnent deux programmes basiques du Ministère de la Santé, l'assistance scolaire pour les élèves et un programme de vaccination gratuite (tuberculose, fièvre jaune...).

Une situation d'isolement et de pauvreté sociale, en partie liée à l'irresponsabilité et l'abandon des pouvoirs publics, incapables d' assurer le développement local. C'est

(8) Une unique ligne de minibus propose trois départs par jour, à l'aube, en direction de La Merced, avec retour en fin de journée. Il s'agit de la nouvelle entreprise de transport "Turismo Palomar ", dotée de 4 véhicules et créée par des habitants du village, dans une initiative locale qui vise à résoudre les problèmes de desserte avec l'extérieur. 
alors la population de El Palomar qui doit s'organiser pour prendre en charge le progrès de la communauté, comme ce fut le cas en 1998 lors du phénomène du Niño. La route allant à La Merced était en partie détruite, isolant totalement le village du reste de la province. Les habitants durent ouvrir une nouvelle voie sur huit kilomètres en comptant sur leurs propres ressources humaines (en pleine période de récolte), avec néanmoins l'aide matérielle de la Municipalité de La Merced et de la mine privée San Vicente. Une initiative villageoise qui répond au détournement d'un budget public qui leur était destiné pour l'emploi d'une main-d'oeuvre abondante.

\section{3. Le problème de la subversion}

La subversion des années 1980/1990 frappa fortement les régions rurales isolées et notamment la partie tropicale. C'est effectivement en 1985 que pour la première fois le groupe terroriste Sentier Lumineux fait irruption dans la zone de El Palomar. L'intérêt économique que représentaient les cultures de café, ainsi que les difficultés pour accéder à ce secteur, en faisait un endroit stratégique pour la guérilla. L'existence d'un revenu lié à la caféiculture offrait la possibilité d'encaisser l'impôt révolutionnaire mis en place par les divers groupes subversifs.

Le Sentier Lumineux ou le MRTA (Mouvement Révolutionnaire Túpac Amaru) obligeaient les paysans à verser une taxe pour financer leurs actions. Le refus de contribution à l'impôt pouvait entraîner de graves conséquences : destruction de parcelles, incendie des récoltes, ou pire encore, assassinat des producteurs ou des membres de la famille. Les paysans devaient faciliter les déplacements des groupes terroristes et ils avaient l'obligation de leur fournir des vivres quand l'occasion se présentait. La guérilla cherchait aussi à recruter pour augmenter ses troupes.

À partir de 1987, face à cette situation de terreur, la majorité des habitants de El Palomar quitte peu à peu leurs terres pour offrir leur force de travail à La Merced, Tarma, Huancayo, Lima ou encore, Arequipa, alors plus sûres que les zones rurales isolées. C'est environ $70 \%$ de la population qui s'enfuit entre 1987 et 1996.

Les plus vieux et les plus pauvres sont ceux qui restèrent. Refusant de collaborer avec l'ennemi et de payer l'impôt révolutionnaire, les paysans avaient souffert de toutes sortes de problèmes : viols, enlèvements, assassinats, destruction de maisons, de champs, des bassins de traitement du café, et de véhicules. Les terroristes faisaient sauter les ponts et bloquaient les routes, ce qui rendait dangereux le transport du café jusqu'à La Merced, principal point de vente.

L'installation en 1992 d'une petite base de l'armée pour lutter contre la subversion engendra en fait une situation confuse et tendue. Toute personne ayant été aperçue avec un terroriste était alors accusée de complicité par les militaires. Inversement, les terroristes accusaient de délateurs quiconque surpris avec un militaire, si ce n'est un vendeur d'épicerie faisant son travail de commerçant. Les paysans étaient alors pris entre deux feux.

Walter Flores, le gérant de l'actuel coopérative, nous raconte : 
“Moi, comme beaucoup, j'ai été victime de la subversion. En 1992, c'est d'abord les militaires qui m'ont accusé de terroriste. Ils m'ont envoyé en prison à Huancayo pendant près de quatre mois. Mais j'étais innocent, ils n'ont donc rien pu prouver, et m'ont alors relâché. Je suis retourné à Sanchirio pour mes cultures de café et le Sentier Lumineux m'a attrapé en me disant que j'étais parti avec l'armée pour dénoncer les terroristes. Tout le village a dû me défendre pour éviter mon exécution sur la place de Sanchirio. Après je suis resté à El Palomar quelques mois, mais la pression était trop forte, $\mathrm{j}$ 'ai dû partir pour presque deux ans ".

Avec les départs massifs pour les centres urbains, les plantations de café se retrouvèrent à l'abandon pendant plusieurs années. La forêt gagnait de nouveau du terrain sur les cultures ainsi que sur les zones inhabitées, changeant peu à peu le paysage local (9).

En 1992, c'est l'arrestation du chef du Sentier Lumineux, Abimael Guzmán. La subversion ne s'arrêtera cependant pas du jour au lendemain. De nombreuses souches de résistance du Sentier Lumineux et des colonnes entières du MRTA restèrent actives jusqu'à la fin de 1995, année où prendra fin progressivement le terrorisme dans la zone rurale de El Palomar (10).

À partir de 1996, pratiquement tous les habitants qui avaient fui leur village y retournèrent pour se dédier de nouveau à la culture du café (5\% des migrants restèrent entre Arequipa et Lima). Presque 10 ans d'abandon des champs cultivés avait conduit les plantations de café dans un état de friche totale. Les caféiers avaient grandi de façon désordonnée, de nombreuses maladies s'étaient installées, les plantes de certaines parcelles avaient été arrachées par les terroristes, si bien que les cultures ne produisaient pratiquement plus rien. El Palomar s'était convertie en une zone d'extrême pauvreté.

Il fallait donc s'organiser pour survivre, car individuellement les paysans n'avaient pas les moyens, ni financiers ni techniques, de surmonter la situation dans laquelle ils se trouvaient. Il s'agissait de remettre sur pied les plantations de café pour qu'elle soient rentables le plus rapidement possible. Il fallait s'approprier de nouveau l'espace pour créer un environnement économique favorable à la population, permettant de s'intégrer socialement dans un territoire plus vaste qu'est la région et, au-delà, la nation. C'est ainsi qu'une partie des agriculteurs fonda une coopérative, ce que nous verrons plus loin.

(9) L'installation de la base militaire avait elle aussi modifié une partie de l'espace. Elle utilise environ 5 hectares de surface cultivable, pour le plus grand désarroi des agriculteurs concernés, privés de leurs cultures. Située sur une portion de terrain qui appartient à deux caféiculteurs, elle occupe effectivement une zone d'altitude aux sols trés fertiles, idéale pour les cafétiers. Aucune indemnité n'avait été proposée par le gouvernement.

(10) Ce n'est pas seulement El Palomar qui avait souffert du terrorisme, mais l'ensemble des secteurs caféiers, que ce soit les petits ou les gros producteurs. Ces derniers avaient aussi connu de graves dégâts, comme la famille Schuller de Villa Rica, pour ne citer qu'elle, dont l'usine d'élaboration du café explosa en 1992. Le problème était général et la production de Chanchamayo chuta pendant ces années-là, plus personne n'osant s'aventurer dans les plantations pour récolter, de peur de rencontrer les terroristes, ou d'être pris sous les tirs croisés des différents groupes. 


\section{LE PROBLÈME DE LA COMMERCIALISATION}

Le café, comme n'importe qu'elle denrée agricole destinée au marché, implique une problématique de filière de production et de commercialisation, où interviennent différents acteurs : les producteurs, les entreprises telles que coopératives, associations ou exportateurs privés et l'État et ses institutions. Engagés dans un vaste réseau, ces acteurs déterminent l'avenir du grain de café.

\section{1. Un réseau bien complexe}

\section{1. 1. Les acteurs du café}

Les premiers acteurs concernés sont évidemment les producteurs, plus particulièrement les petits producteurs puisque ce sont eux les plus nombreux. Tout à fait insérés dans les dynamiques régionales, ils dépendent cependant de facteurs extérieurs caractéristiques d'une économie mondialisée. Ils sont à la base d'un système qui fonctionne en réseau et dont ils sont à l'origine de l'existence, mais ils en représentent pourtant la périphérie.

Individuels ou organisés en coopérative comme les petits caféiculteurs de la communauté de El Palomar, ce sont eux les responsables de la qualité du café. Bien que produisant un café de grande qualité, les petits paysans de El Palomar sont l'extrême périphérie du réseau, dans un pays lui-même à la périphérie d'une économie mondialisée. Ils reflètent la marginalité absolue dans la globalité.

Ensuite, interviennent les intermédiaires locaux, acheteurs privés qui profitent d'un système établi pour jouer un rôle hautement lucratif qui concerne la négociation des prix du café aux producteurs. Au début de la chaîne de la commercialisation, ils sont eux-mêmes dépendants de la demande des exportateurs à qui ils revendent le café.

Ces derniers sont en fait la clé du réseau. Ces entreprises privées appartiennent à un lobby très puissant qui régule les tarifs internationaux du café, fixés et déterminés à la bourse de New York. Influant sur la politique tarifaire du café, ce lobby profite du faible prix décidé pour le café péruvien pour réaliser des marges énormes (11). Le prix du quintal de café vert au Pérou connaît effectivement une sous-évaluation de 15 dollars par rapport au tarif international, conséquence de sa mauvaise image entretenue aussi pour des raisons économiques.

C'est dans les nations occidentales, principales consommatrices, où s'achemine le café, que se termine la chaîne de la commercialisation. On est en présence du vieux schéma commercial classique d'une économie globalisée qui relie les pays pauvres de la périphérie (producteurs de matières premières) aux pays occidentaux (consommateurs).

Puis se greffe sur le réseau l'État et ses institutions qui sont censés jouer un rôle déterminant dans le processus de développement de la culture du café. Il s'agit du Ministère de l'agriculture en ce qui concerne la production et l'obtention de crédits et de PROMPEX (Promotion des Exportations), dont la dénomination résume la vocation.

(11) À La Merced, les principaux exportateurs sont : Romero Trading, Luis Dreyfus, Coinca, Inversiones Luna et Aicasa. 
D'autres associations, entreprises ou ONG peuvent aussi entrer en jeux dans le but d'aider les petits agriculteurs à miser sur la qualité ou à s'introduire de façon adéquate sur le marché mondial, comme ce fut le cas entre ADEX et El Palomar. Nous revenons sur ce point ultérieurement.

\section{1. 2. La filière traditionnelle}

Dans la zone de El Palomar, les agriculteurs produisent aujourd'hui un café de très bonne qualité qui rentre dans la catégorie des " cafés spéciaux ". Manquant de débouchés, ils sont cependant contraints, tout comme la majorité des caféiculteurs de la région, de vendre leur récolte sur le marché de La Merced, dont le commerce est aux mains des intermédiaires.

Le prix payé par les intermédiaires ne récompense pas les efforts entrepris pour fournir un produit de qualité. Pendant la campagne de l'année 2000, le prix d'un kilo de café sec (12) fut en moyenne de 3,50 soles. Pour 2001 il chuta à 2,50 soles le kilo.

Si le prix reste élevé par rapport aux autres denrées agricoles, le rendement à l'hectare étant faible pour les plantations traditionnelles (1 000 kilos de café sec dans le meilleur des cas), une fois déduits les coûts de production, les bénéfices sont finalement maigres et se rapprochent de ceux obtenus avec un hectare de pomme de terre qui produit autour de 20 tonnes dans de bonnes conditions.

La période critique pour les petits caféiculteurs de Sanchirio ElPalomar concerne les mois avant la récolte (janvier à mai), pendant laquelle l'économie rurale est au plus bas, l'argent des ventes de la production précédente s'étant généralement épuisé (13). Pendant cette période il est fréquent que les petits agriculteurs offrent leur force de travail à La Merced, dans des activités aussi diverses que la maçonnerie, la charpente, les services de charge pour les transporteurs, ou encore comme ouvriers saisonniers dans les plantations des gros producteurs pour l'entretien de caféiers. Ces migrations sont obligatoires pour le maintien de l'économie familiale, bien que sporadiques car les plantations des petits paysans ont aussi besoin d'une attention particulière tout au long de l'année.

En passant par le circuit des intermédiaires, la culture du café devient de moins en moins rentable. Si le prix était meilleur, les ventes du café permettraient le soutien de la famille durant tout le reste de l'année.

Seuls les gros producteurs, comme la famille Brack ou Schuller, de la province voisine de Oxapampa (district de Villa Rica), travaillent directement avec des exportateurs qui placent leur café sur les marchés américains et allemands. Cependant, les frais de gestion restent souvent en dehors des possibilités des petits agriculteurs, mais c'est surtout les démarches administratives, la promotion du produit, l'organisation et la mise en place d'un tel système commercial, qui leur échappent. Ils ont donc beaucoup de

(12) Un quintal de café sec contient 55,2 kilos qui équivaut, après avoir enlevé la dernière écorce à un quintal de 46 kilos de café vert.

(13) À La Merced une entreprise d'exportation, Romero Trading, propose alors des prêts prérécolte, aux intérêts cependant usuriers, largement défavorables aux paysans (4,50\% mensuel). 
difficultés pour se défaire du réseau producteurs/intermédiaires/exportateurs qui constitue le schéma classique de l'exploitation du centre sur sa périphérie.

\section{2. Enjeux et stratégies}

\section{2. 1. Enjeux}

Comme matière première agricole exportable de grande valeur commerciale, le café représente un enjeu important. Sachant que $90 \%$ de la production du Pérou est vendu à l'étranger, il rapporte un grand nombre de devises au pays, permettant ainsi son intégration dans le réseau économique mondial. C'est un produit porteur pour le commerce extérieur péruvien, dans la mesure où l'importance des volumes exportés va de pair avec un tarif adéquat.

Face à de tels enjeux, les stratégies pour réussir une meilleure intégration sur le marché international et national sont diverses ; il incombe aux différents acteurs de les mettre en place et elles interviennent aussi à des niveaux distincts du réseau (14).

Il revient donc au gouvernement et à ses différentes institutions de promouvoir ce produit face au marché extérieur, mais aussi interne, pour en obtenir la meilleure acceptation et la meilleure rentabilité.

Le but est bien d'améliorer la qualité et l'image du café péruvien sur la scène internationale pour en élever le prix et récupérer le tarif officiel de New York, voire le dépasser comme c'est le cas pour certains pays tel que El Salvador ou Costa Rica. Engendrer plus de devises, mais aussi aider le paysannat à avoir un meilleur revenu, sont les orientations que doivent prendre les institutions publiques et privées, pour résorber en partie les problèmes du sous-développement. En effet, une plantation bien gérée avec des variétés adéquates et une bonne utilisation d'engrais organiques, peut permettre d'accéder à un bon prix sur le marché international, quand la qualité du café parvient finalement à être reconnue par les acheteurs et les exportateurs.

Mais les enjeux pour les exportateurs sont très grands, puisqu'une hausse sur le marché international du prix du café ne signifie pas directement une augmentation correspondante pour les producteurs. Il s'agit d'un problème de répartition et de redistribution des bénéfices réalisés entre l'étape de la production et celle de la commercialisation, où l'intermédiaire et l'exportateur profitent de leur pouvoir économique pour jouer sur la fluctuation des prix du café et obtenir ainsi les meilleures marges possibles entre les deux étapes. C'est alors les petits producteurs, comme à Sanchirio El Palomar, qui souffrent le plus des conséquences de ce système. C'est le cas typique d'échange inégal entre le centre et sa périphérie, avec un processus d'accumulation au centre.

Le prix payé aux petits producteurs doit être convenable, car dans de nombreuses zones le café est une culture alternative à la coca. Une trop grande chute des tarifs peut rapidement entraîner l'abandon des plantations caféières pour des champs de coca, alors

(14) Comme nous pouvons le noter dans la citation de Adam Puyes Puyes (ingénieur agronome au Ministère de l'Agriculture de Chanchamayo), elle-même inspirée de la politique du Ministère, "l'organisation, la production et la commercialisation sont les trois piliers de la caféiculture". 
beaucoup plus rentables pour les producteurs. Il en découle des conséquences néfastes pour la région et le pays, avec tous les problèmes de narcotrafic, de corruption et d'insécurité, déstabilisant très vite l'économie et la société (15). Sur le territoire de El Palomar la coca n' a pas encore fait son apparition, mais les grandes zones productrices ne sont pas loin et l'influence d'une culture aussi lucrative ne peut que trop rapidement se faire sentir.

L'enjeux pour l'État est donc très important. Il doit assurer l'exportation de grands volumes pour engendrer une entrée suffisante de devises et permettre aussi le développement des zones concernées, dont la population qui participe effectivement à la mise sur le marché d'un produit qui se place dans le groupe de tête des exportations, doit bénéficier des infrastructures adéquates. Il s'agit d'un rapport de forces entre l'État et les producteurs pour une bonne gestion des ressources et l'application de politiques cohérentes. L'intégration efficace au marché des populations marginales productrices de café, comme les paysans de Sanchirio, est un enjeu indispensable pour leur survie.

\section{2. 2. Stratégies de la part de l'État}

PROMPEX est l'institution qui s'occupe actuellement de la rubrique de la promotion des produits du pays, mais son oeuvre n'est cependant pas suffisamment étendue et généralisée pour avoir un effet positif sur l'ensemble des caféiculteurs. Sa principale action a été d'encourager et d'aider à la constitution d'association de producteurs, facilitant la motivation des participants en contribuant à la réalisation d'activités d'intérêt commun.

C'est le cas pour l'association privée APECAFÉ (Asociación Peruana de Cafés Especiales) qui regroupe quelques coopératives sur l'ensemble du territoire et dont le but est de sensibiliser ses associés à redonner une bonne image du café péruvien en garantissant un produit de très bonne qualité, permettant alors l'accès à un meilleur prix en entrant sur un marché spécialisé. Cependant l'adhésion à $A P E C A F E ́$ reste élevée, ce qui décourage les petites coopératives aux ressources limitées de s'y inscrire, prétextant aussi le peu de résultat jusqu'à présent en ce qui concerne la commercialisation et les projets réalisés. Les caféiculteurs de El Palomar ne font toujours pas parti de APECAFÉ.

Le plus gros effort du gouvernement se résume par la mise en place du projet $P R O C A F E$, dirigé par le Ministère de l'Agriculture. Il s'agit d'un programme visant à venir en aide aux petits et moyens producteurs de café, dans les zones fortement touchées par le terrorisme. Élever le niveau de vie des paysans en installant un développement durable de la culture du café, permettant de se positionner de nouveau dans l'économie nationale, tels sont les enjeux de ce vaste programme.

Pour atteindre ces objectifs, le Ministère a élaboré un système de crédits rotatifs de $1,5 \%$ d'intérêts mensuels, distribués sous forme d'engrais, biologiques pour la plus grande partie (guano et roche phosphorique). Les prêts sont effectués en début de saison (février) et remboursables en argent après les récoltes (septembre), selon la valeur de l'engrais au moment de l'approvisionnement.

(15) Aujourd'hui le Pérou compte environ 65000 hectares de coca. 
Dans la province de Chanchamayo, le Ministère de l'Agriculture travaille depuis 1998 sur ce projet en collaboration avec l'agence locale de ADEX (Association des Exportateurs), dont les ingénieurs de La Merced apportent une assistance technique gratuite deux fois par mois, pour l'ensemble de la coopérative de El Palomar, dans le cadre du programme de Développement Alternatif (D.A.) réalisé en coopération avec USAID. Une grande partie des subventions proviennent de la commission étatique CONTRADROGAS (Commission de Lutte Contre la Drogue). Le but est d'homogénéiser la qualité du café pour obtenir une production adéquate qui soit directement exportable et aider ainsi les paysans à prendre en charge la commercialisation, en trouvant des filières d'exportation. Il s'agit bien de promouvoir cette culture, au niveau international, en organisant les agriculteurs dans une optique d'insertion du paysannat dans un schéma qui irait de la production à la commercialisation, en trouvant des débouchées sur le marché extérieur.

C'est finalement en 1999 que le programme PROCAFÉ porta ses fruits. L'agence ADEX, fonctionnant sur le projetD.A.-USAID, réussit à mettre en rapport la coopérative de El Palomar et autres groupes de petits producteurs, avec une entreprise des ÉtatsUnis, la Seattle Best Coffee, pour réaliser une vente sans passer par les intermédiaires locaux. La Seattle Best Coffee, spécialisée dans l'achat de café de très grande qualité, assura un prix supérieur d'environ $15 \%$ à celui du marché local, justifié par l'origine et la qualité du lot. El Palomar put alors exporter en direction des États-Unis 200 quintaux (9 tonnes de café vert) sur un total de 375 quintaux embarqués. Malheureusement, cette expérience ne fut pas répétée, El Palomar et les autres coopératives qui participèrent à l'événement s'en remettent de nouveaux aux intermédiaires locaux.

On peut alors se demander pourquoi cette alternative fonctionna seulement une année. Les paysans de El Palomar n'auraient-ils pas respecté les normes de qualité ?; les institutions étatiques ne se sentent-elles pas concernées par l'avenir des ces agriculteurs ?; ou le marché spécialisé du café de grande qualité est-il trop réduit ? Il semble que ce soit en fait les circonstances locales qui font que ce programme prend fin, car fonctionnant avec un budget de CONTRADROGAS et la province de Chanchamayo n'étant pas réellement concernée par la culture de la coca, l'action de ADEX-DA se déplace à d' autres régions. Cependant, ce genre de politique comporte des risques, parce que le café doit être une culture alternative à la coca et pas l'inverse. Pour l'année 2000 c'est la province de Quillabamba (Cusco) qui bénéficia d'une commande de la Seattle Best Coffee d'environ 1000 quintaux de café vert.

El Palomar est maintenant abandonnée des institutions publiques. De plus, de graves problèmes de corruption au sein de l'agence locale du Ministère de l'Agriculture ont affecté négativement le bon déroulement du programme PROCAFÉ.

L'État au Pérou ne joue donc qu'un faible rôle en ce qui concerne l'essor du café. Il est des pays, comme le Venezuela (Tulet et al., 1994), le Mexique ou le Costa Rica, où l'État et ses institutions ont favorisé l'encadrement de la production, la prise en charge de la commercialisation, l'intervention au niveau du système de crédit, la gestion de caisses de stabilisation des prix, ou encore la diffusion des innovations techniques (16) (Beaumond \& Daviron, 1990).

(16) En effet, au Venezuela l'institut d'État FONCAFÉ gérait à la fois la commercialisation du café en appliquant une politique de régulation tarifaire. Au Mexique, c'est l'institut IMECAFÉ qui 


\section{3. Les stratégies des producteurs}

\section{3. 1. L'association de producteurs : homogénéiser et améliorer la qualité}

Le regroupement des agriculteurs est de toute façon une alternative pour améliorer la qualité du café. La réforme agraire avait effectivement eu des effets négatifs sur la production d'un café de bonne qualité. La parcellisation des haciendas entre différents agriculteurs entraîna la diversification des moyens, des méthodes et des techniques de production. Ainsi, de nature uniforme au départ, car produit par la même entreprise, les caractéristiques du café devinrent vite hétérogènes d'une zone à l'autre, abaissant considérablement la qualité pour l'ensemble de la région. Le café perdit de sa valeur aux yeux des acheteurs, les paysans décidèrent alors de consolider leurs rapports pour rester compétitifs sur le marché international, dans un processus d'intégration régional primordial pour la pérennité du groupe.

C'est ce que firent les agriculteurs de la zone de El Palomar en 1978 en se regroupant autours de la coopérative du même nom, pour uniformiser la production et améliorer la qualité. Elle regroupait environ 250 familles originaires de différents secteurs de la communauté. La bonne qualité du café, l'organisation efficace des membres de la coopérative et la politique favorable du gouvernement, permirent de vendre directement la production à l'étranger (Europe et Japon) à un prix tout à fait correct sans passer par les intermédiaires locaux. La coopérative El Palomar connut ainsi une phase de prospérité jusque dans le milieu des années 1980. Puis progressivement, les dirigeants achetèrent du café bon marché (et moins bon) dans le nord du pays pour le mélanger avec la production de la zone, pensant faire ainsi de plus grands profits. La qualité se dégrada rapidement, les clients arrêtèrent peu à peu les commandes, les dirigeants s'enfuirent avec une partie du capital et pour couronner le tout, la vague du terrorisme s'empara de la région. La coopérative déclina très vite, en 1986 elle avait totalement disparu et la majorité des caféiculteurs avait abandonné leur champ.

À la fin 1997, une partie des agriculteurs qui avait regagné leurs terres s'associa de nouveau en une coopérative de caractère privé, dénommée Entreprise Communale de Services Agricoles (ECOMUSA) El Palomar. Le but est d'améliorer les techniques de production, de récolte et d'élaboration du café sec, pour obtenir un produit dont la qualité supérieure justifie un prix plus élevé. Cependant, acquérir la reconnaissance officielle de la grande valeur de son café, pour pouvoir entrer dans un marché autre que le conventionnel, comme celui des produits de luxe, organiques, ou sur le marché solidaire, est un processus qui prend du temps et qui demande beaucoup d'énergie et d'organisation.

Constituée d'une cinquantaine de producteurs associés et d'une centaine de bénéficiaires secondaires, l'entreprise put alors louer les services d'un ingénieur

\footnotetext{
s'occupait d'acheter le café aux différents producteurs à un prix raisonnable pour l'exporter ensuite. Dans les deux cas, les intérêts en jeu et les trop grandes sommes d'argent engagées, ont fini par corrompre les responsables des divers secteurs, ce qui a mené à l'échec ces vastes programmes d'État, pourtant très efficaces au départ. Au Pérou, le projet de création de IPECAFÉ (Instituto Peruano del Café), organisme similaire à ceux cités ci-dessus, se retarde chaque jour un peu plus, enrichi des mauvaises expériences de ces confrères producteurs.
} 
agronome spécialiste en café, pour commencer à réhabiliter les cultures, donnant des cours de formation et favorisant l' assistance technique. En 1999 la ECOMUSA réussit à faire partie du projet $P R O C A F E$. Être organisé est effectivement une condition pour recevoir l'aide gouvernementale.

\section{3. 2. Café biologique}

Aujourd'hui l'entreprise communale El Palomar est en restructuration. La majeur partie des associés veut maintenant se consacrer à produire du café biologique dont le prix sur le marché international est meilleur que celui du conventionnel, dans la mesure où une filière commerciale peut être ouverte. Ainsi depuis le mois de juin 2001, cinquante des associés initiaux ont créé une nouvelle entreprise communale, Sanchirio Organic Coffee. Cette nouvelle coopérative s'est mise en rapport avec une association de certification biologique allemande, Naturland, qui octroie un label de culture biologique après inspection des caféières. La première visite a eu lieu en juillet 2001, mais il faut compter entre deux et trois ans pour recevoir le label définitif. Un processus long et strict mais qui peut dans l'avenir aider les paysans de Sanchirio à retrouver un prix adéquat pour leur café et s'intégrer ainsi parfaitement sur le marché mondial. Ils sont en train de prendre exemple sur la coopérative La Florida qui a une longue expérience de la culture biologique et dont les terres sont frontalières avec El Palomar.

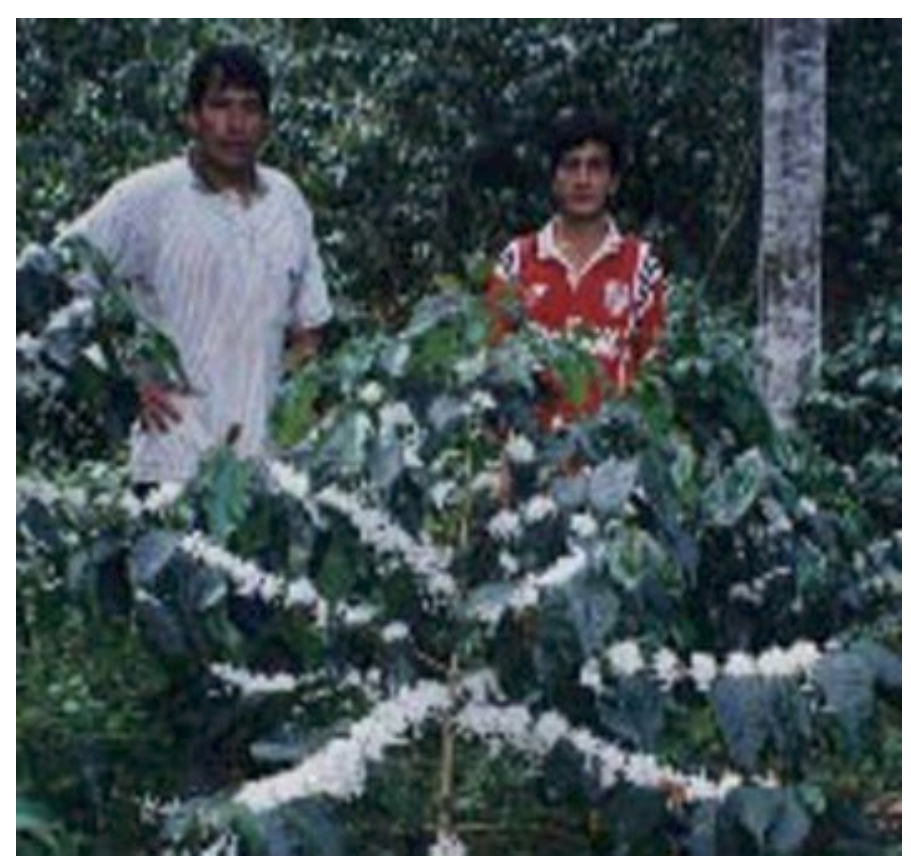

Fig. 4 - Un caféier en fleurs dans une parcelle biologique. 


\section{3. 3. Café torréfié pour le marché intérieur}

Une autre stratégie consiste à torréfier et moudre le café récolté, alors prêt à la consommation pour le marché intérieur. Engendrant de la valeur ajoutée au produit initial, les bénéfices rapportés par les ventes sont alors beaucoup plus importants et permettent de couvrir largement les coûts de transformation, en rétribuant les paysans avec un meilleur prix, sans passer par les intermédiaires locaux. C'est ce que font depuis le mois de novembre 2000 quelques membres de la coopérative El Palomar, en transformant une partie de la production et en se chargeant de la vente par l' intermédiaire de foires, d'installation de stand dans divers endroits et par la vente directe à des institutions publiques ou privées. Le marché national étant cependant très réduit, il n'est pas possible d'y écouler toute la récolte d'une année. Il reste alors à promouvoir et encourager la consommation interne de la part des organismes de l'État, pour réussir une meilleure intégration au marché national.

S'introduire sur le marché national requiert aussi un travail commercial, de diffusion et d'information, souvent compliqué pour les agriculteurs habitués à vendre une matière première et non un produit fini. C'est une nouvelle mentalité et une restructuration par laquelle les caféiculteurs doivent passer pour bien prendre en charge un tel commerce, qui signifie aussi devoir immigrer en zone urbaine (au moins temporairement) et avoir un comportement de vie différent.

\section{3. 4. Diversifier la production}

La diversification de la production est aussi un autre moyen d'échapper aux faibles prix du café et d'être moins dépendant des facteurs commerciaux externes. Associer aux caféiers d'autres cultures à forte valeur, comme a fait un temps le Guatemala avec l'introduction de la cardamome dans les plantations (Tulet \& Girard, 2000), représente en effet une solution aux périodes de chute des prix du café. Au Pérou c'est la uña de gato qui pourrait occuper l'espace aux côtés du café, dans les zones basses comme dans la vallée voisine de Satipo. Cette liane aux propriétés curatives multiples et renommées, connaît ces dernières années une expansion importante sur le marché international, dont pourraient profiter les petits agriculteurs.

À Sanchirio El Palomar, trop haut pour la uña de gato, c'est le commerce du bois qui est en cours d'étude. Étant donné que tous les caféiers grandissent à l'ombre de grands arbres, il suffit d'y associer en forme rotative un bois rentable pour la vente, mais aussi adaptable au terrain. C'est le cas d'une variété de lauriers et d'une variété d'eucalyptus, qui à la dixième année de plantation produisent une quantité de bois d'une valeur d'environ 150 soles par arbre et par an dans de bonnes conditions de rotation des unités (une centaine d'arbres peuvent rentrer dans une caféière de un hectare). Les membres de la coopérative de Sanchirio Organic Coffee sont actuellement en discussion pour implanter ces variétés, d'autant plus qu'ils ont l'opportunité de recevoir des graines d'un gros caféiculteur voisin, Fransisco Brack, l'assistance technique de son ingénieur et les facilités pour s'introduire sur le marché du bois.

Comme complément aux revenus du café, quelques agriculteurs commencent aussi à se lancer dans la culture de l'ananas qui, malgré son prix modéré, donne une 
production tous les mois et assure ainsi un petit pécule utile aux besoins quotidiens. Les plantations de piment rouge qui produisent de façon régulière sont aussi parfois cultivées pour le marché local.

\section{4. Le commerce équitable, la solution idéale}

Naissant dans les années 1980, il s'agit d'une nouvelle forme de commerce qui vise à sensibiliser les populations des pays consommateurs à connaître l'origine des denrées qu'ils achètent et les conditions de vie des gens qui les produisent. Le but est de créer un lien direct entre l'agriculteur et le consommateur, en éliminant les intermédiaires. La production est achetée à un tarif minimum supérieur d'environ $30 \%$ aux cours internationaux, dit "tarif juste ", redistribuant ainsi un salaire convenable aux petits paysans du tiers-monde, améliorant peu à peu leur condition de vie. Il s'agit bien d'un réseau d'entraide entre les petits agriculteurs des pays pauvres et les consommateurs des pays occidentaux, sensibilisés aux problèmes de développement et d'exploitation, où le produit fini se vend généralement dans le circuit d'un marché appelé “solidaire ", à un prix lui aussi légèrement plus élevé. Les gros producteurs n'entrent pas dans ce genre de projets.

C'est l'association Max Havelaar de Hollande, créée en 1988, qui représente le pionnier en la matière de commerce équitable, dont l'action principale se déroule justement dans le cadre du café. Elle permet à de nombreux petits producteurs d'entrer directement sur le marché européen, avec la garantie d'un prix juste pour leur récolte. Cet organisme réalise une supervision de la zone de culture pour vérifier les conditions du développement et octroie un label aux producteurs ainsi qu'à des torréfacteurs européens et/ou importateurs qui s'engagent à respecter les fondements du commerce équitable. Les petits agriculteurs s'engagent, eux aussi, à fournir un café de grande qualité qui justifie un prix d'achat supérieur. Ce commerce est alors équitable pour le producteur qui reçoit une meilleure rétribution pour son travail, mais aussi pour le consommateur qui va pouvoir apprécier un café haut de gamme.

Cette alternative est une réponse au manque de politique adéquate des gouvernements locaux pour la promotion et la valorisation de leur café. C'est aussi une solution à l'instabilité des cours mondiaux, qui atteignent parfois des seuils si bas qu'ils ne permettent pas aux petits agriculteurs de couvrir les coûts de production.

Le marché du commerce équitable est pour l'instant réduit, mais d'année en année les quantités exportées augmentent ainsi que le nombre de participants, producteurs comme torréfacteurs/importateurs. De 7000 tonnes de café vert vendues en 1992, les exportations du commerce équitable sont passées à 13000 tonnes en 1996. À El Palomar, l'entreprise communale Sanchirio Organic Coffee est en négociation avec Max Havelaar pour l'obtention du label.

C'est pour l'instant une association humanitaire française, SALDAC (Solidarité avec l'Amérique Latine pour le développement Autonome des Communautés) qui s'est connectée avec la nouvelle entreprise, Sanchirio Organic Coffee, pour mettre en place un projet de commerce équitable. SALDAC s'engage à acheter le café à un tarif presque deux fois supérieur à celui du marché local, mais les agriculteurs doivent aussi faire 
l'effort de fournir un café d'excellente qualité, respectant les normes de sélection et de transformation, pour lesquelles un contrôle très strict est mis en place par les petits caféiculteurs eux-mêmes, conscients de l'importance de ce travail. Effectivement, la grande qualité du café stocké pour SALDAC est la condition essentielle pour la réussite de ce projet et l'ouverture du marché français. La récolte d'un café biologique, pour lequel la coopérative est en attente d'obtention du label de Naturland, est aussi un des critères indispensables. Les contraintes de production et d'élaboration sont donc grandes pour ces agriculteurs, mais leurs efforts sont ensuite récompensés par un prix qui valorise leur travail.

Ce programme de commerce équitable a débuté avec la campagne 2001 pour laquelle l'association française a fait une commande équivalente à 7 tonnes de café vert (environ $10 \%$ de la production totale de l'entreprise communale Sanchirio Organic Coffe). L'association se charge ensuite de la distribution du produit fini en France. Cette action est un espoir pour les petits caféiculteurs de El Palomar de pouvoir échapper, au moins en partie, à l'exploitation internationale d'un commerce globalisé, aux règles et lois ajustées à l'intérêt des groupes dominants, même si pour l'instant ce projet ne concerne que 50 familles du secteur.

\section{CONCLUSION}

Les caféiculteurs de El Palomar ont donc connu une histoire très mouvementée. Organisés au début des années 1980 en une grande coopérative qui bénéficiait d'un prix

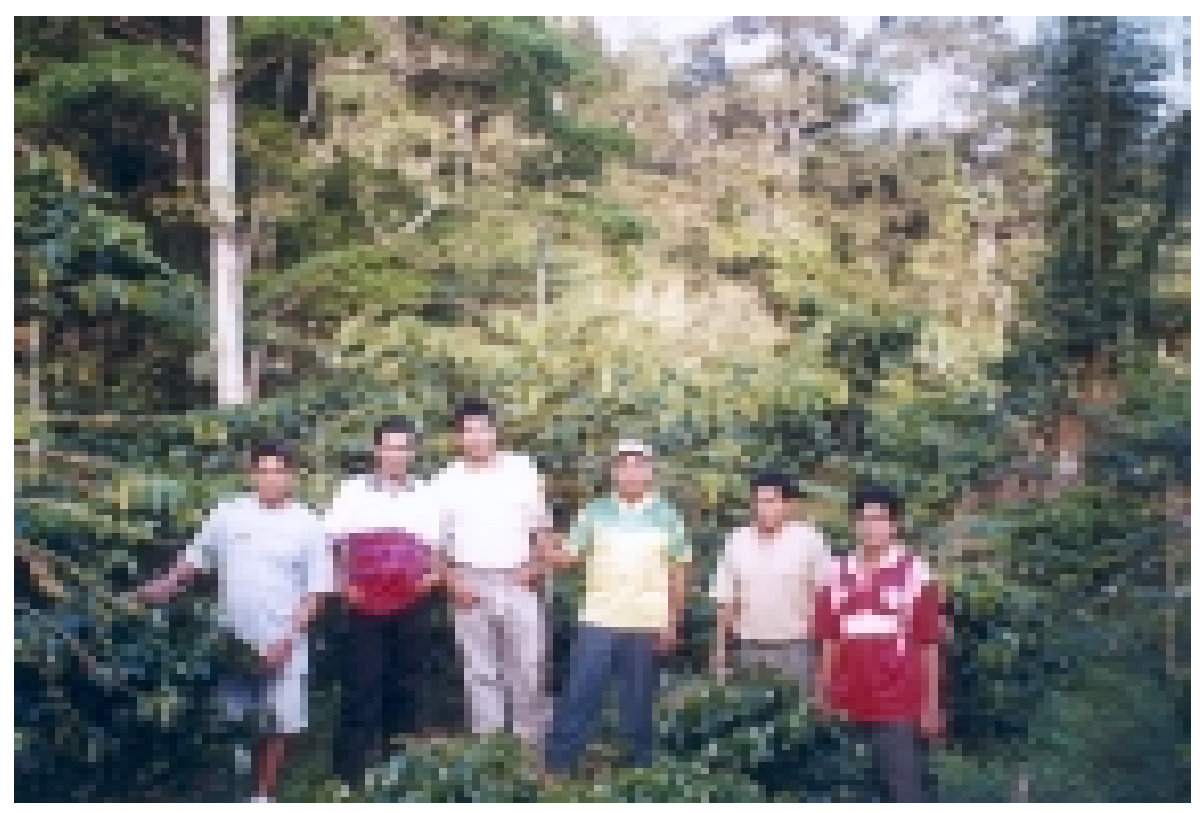

Fig. 5 - Des producteurs de la nouvelle coopérative Sanchirio Organic Coffee, réunis dans un des champs de café. 
correct grâce à un marché en Europe et au Japon, la situation s'est vite dégradée. La corruption des dirigeants de la coopérative, mais surtout l'irruption du terrorisme dans la région, mit fin à cette entreprise et obligea la majorité des agriculteurs à abandonner leur culture et à fuir dans les zones urbaines.

À leur retour après plusieurs années, les champs en friche ne produisaient plus et El Palomar s'était converti en une zone d'extrême pauvreté. Les caféiculteurs de El Palomar, tout comme la majorité des petits producteurs du Pérou, s'en remettent aux intermédiaires locaux pour vendre leur café à un prix beaucoup trop faible qui ne justifie pas les coûts de production.

Se regroupant de nouveaux en une entreprise communale, une partie des agriculteurs profita d'un programme de l'État en matière d'assistance technique et de commercialisation, qui malheureusement ne fut qu'éphémère.

Produisant aujourd'hui un café biologique de très grande qualité, l'espérance des petits agriculteurs de Sanchirio El Palomar repose actuellement sur le commerce équitable, qui semble l'unique solution pour échapper à l'insupportable monopole des intermédiaires et aux dures lois des groupes dominants. Cependant ce marché sera-t-il assez grand pour absorber l'intégralité de la production de la zone ?

Une concertation entre tous les acteurs du café est indispensable pour réussir une politique cohérente et mettre en oeuvre une action qui permette l'intégration des petits producteurs à un marché mondial pourtant très prometteur. Énormément consommé, le café, source de devises, est effectivement une culture qui offre un réel potentiel pour le développement des pays et des populations concernés.

D'ailleurs, comme le souligne l'association $A P E C A F E ́$ dans une phrase symbolique : “au Pérou l'or pousse sur les arbres ”, il suffit alors de savoir en récolter les fruits.

\section{Références citées}

BARCLAY, F., 1989 - La colonia del Perené, 258p. ; Iquitos : CETA (Centro de Estudios Teológico de la Amazonía).

BARCLAY, F. \& SANTOS GRANERO, F., 1995 - Ordenes y desórdenes en la selva central, historia y economía de un espacio regional, 366p.; Lima : IEP.

BEAUMOND, A. \& DAVIRON, B., 1990 - Le café du Veracruz. In : La dimension économique, dynamique des systèmes agraires : 229-245 ; Paris : ORSTOM.

CARAVELLE : Cahiers du Monde Hispanique et Luso-brésilien, 1993 - Les cultures du café, 292p. ; Paris : IPEALT, numéro spécial 61.

GIROT, P. O., 1984 - L'économie caféière à San Ignacio, Pérou, 23p. Conférence lue lors du symposium pré-congrès UGI tenu à Bordeaux Talence du 22 au 25 août 1984, intitulé : développement dans les pays tropicaux.

TULET, J.- C. \& GILARD, J., 2000 - La fleur du café, 340p. ; Paris : Karthala.

TULET, J.- C., CHARLERY, B., BART, F. \& PILLEBOUE, J., 1994 - Paysanneries du café des hautes terres tropicales, 370p. ; Paris : Karthala. 